Toni Carbo

\title{
Models for Ethical Decision-Making for Use in Teaching I nformation Ethics: Challenges for Educating Diverse I nformation Professionals
}

\begin{abstract}
:
Teaching Information Ethics to a very diverse group of graduate students working towards careers as information professionals raises a number of challenges. The students come from different disciplines and a wide range of diverse educational, economic, social, and cultural backgrounds and from several different countries. At the University of Pittsburgh, students in the Information Ethics course are enrolled in one of three master's or doctoral degree programs at the School of Information Sciences: information science, library and information science or telecommunications. In addition, graduate students, and an occasional senior-level undergraduate student, from other disciplines and schools, such as business, medicine, public and international affairs, as well as students from other universities, such as Carnegie Mellon University, take the fifteen-week course. Identifying and using models for ethical reflection and moral decision-making requires drawing on materials from several disciplines and adapting those models for the course. This paper will discuss some of the models used in the past, the advantages and disadvantages of the model currently used (i.e., Richard Paul and Linda Elder's, The Miniature Guide to Understanding the Foundations of Ethical Reasoning. The Foundation for Critical Thinking, Dillon Beach, CA, 2003), and the evolution of the Information Ethics course over its fifteen-year history.
\end{abstract}

\section{Agenda}

Introduction

Background

SIS Information Ethics Course

Models for Ethical Decision-Making

Context

The Wheel

Selected Frameworks

Models used in SIS Class

Challenges of Teaching Diverse Students

Composition of the SIS Student Body

\section{Author:}

Prof. Toni Carbo:

- School of Information Sciences and Graduate School of Public and International Affairs, University of Pittsburgh, 135 N. Bellefield Avenue, Pittsburgh, PA 15260 USA

- $\square \underline{\text { tcarbo@mail.sis.pitt.edu }}$ 


\section{Introduction}

Teaching Information Ethics to a very diverse group of students, both graduate and undergraduate, most working towards careers as information professionals, raises a number of challenges. The challenges relate to determining the most effective methods to teach the complex subject of Information Ethics and to meeting the varied and often-changing needs of a very diverse group of students. This paper describes some experiences from teaching Information Ethics at the School of Information Sciences at the University of Pittsburgh in Pittsburgh, Pennsylvania, USA and discusses approaches taken to incorporating various models for ethical reflection and moral decision-making used in the course. The perspective is a personal one from an individual who has lived and worked in the United States and in the United Kingdom. It is a Western and Northern based perspective, although through extensive international experience and the participation by many students from outside the U.S. some insights have been gained into different cultural views and experiences.

\section{Background}

After nearly 20 years of working in libraries and with producers and publishers of information resources and observing or participating in discussion of ethical issues related to the information professions, in 1981 when I was working as Executive Director of the U.S. National Commission on Libraries and Information Science (NCLIS), I somewhat naively asked whether a code of ethics for the information professions, writing in an Endnote in the Bulletin of the American Society for Information Science (Bearman, 1981, ). A Society member wrote to tell me that ASIS had a code of ethics but it had lain dormant for some time and little attention or publicity had been paid to it. In June 1990, after a period of years of effort to revise it, ASIS completed its Guidelines (Barnes, 1990).

Throughout my years at NCLIS I had the opportunity to visit scores of libraries, companies and organizations that produced information sources, and numerous other groups and to participate in conferences of professionals. Through this experience, it became clear that many issues arose. These issues ranged from how best to meet the needs of an increasingly diverse and multicultural society; to how to balance the protection of personally identifiable, proprietary, or security information with needs for access to public information (for example privacy and security concerns); to preserving print and electronic resources; to how best to provide equitable access to individuals with disabilities; to archiving and providing access to data from land and weather satellites when satellites were sold to the private sector; to a myriad of other complex issues.

In 1986 when I became Dean of the School of Information Sciences (SIS) (then the School of Library and Information Science), I worked with Professor Stephen Almagno, O.F.M., to develop a course on Information Ethics, beginning with the SIS Dean's Forum on Information Ethics. On January 26, 1989, the school hosted its first lecture. Presented by the Reverend Robert Drinan, S.J. Professor of Law and faculty advisor to the Georgetown Journal of Legal Ethics and former U.S. Representative from Massachusetts, the lecture, "The Ethics of Information in Society," helped provide the basis for thinking about the course. The forum continued with a series of experts from John Leo (of the University of Rhode Island, who spoke on Robert Mapplethorpe), to Pamela Samuelson, (then professor of Law at the University of Pittsburgh, who questioned: "Who Owns Information?"), to Martin Walker (then U.S. bureau chief of The Guardian, who spoke on "Ethics and the Media"), the forum has attracted a diverse audience from the larger academic and community and has helped to shape the course. Vice-Provost Elizabeth Baranger described the forum as "what a university is all about."

In the fall of 1990, we introduced a master's level course, team taught be Almagno and Carbo, initially called, "The Ethics of Information in Society," to educate students about ethical issues in the Information Profession. Over the years as the course has evolved, it has attracted students from all three SIS programs -- Library and Information Science, Information Science, and Telecommunications at both the master's and $\mathrm{PhD}$ levels, as well as students from business, law, psychology, public and international affairs, and other programs, as well as students from Carnegie Mellon University. Prof. Almagno taught the course, with my participation, and, after his retirement in 2001, I have taught the course.

In 1996, to recognize and honor Prof. Almagno, SIS established the Information Ethics fund and contributions were received from foundations and individual, including many alumni, to support: an Information Ethics Fellowship, acquisition of print 
and non-print information resources; travel expenses and honoraria for Dean's Forum Speakers; and participation in information ethics conferences. More information is available on the School's website (http://www.sis. pitt.edu/ ethics).

\section{SIS Information Ethics Course}

The course, now called "Information Ethics," seeks to provide a background to applied ethics as a prelude to learning the skills of ethical decisionmaking and, then, to applying those skills to the real and current challenges of the Information Profession. The scope of the coursework and discussions includes decision-making and challenges related to information sources and services in all formats and media; to the Internet and other digital sources (cyber ethics); and to information-related topics in management. The objectives of the course, described as what students will be expected to have at the completion of the course, are:

- Developed a better understanding of themselves (in the ongoing endeavor to "Know thyself");

- Learned how to identify an issue, reflect on it (which is ethics) and make a decision that is moral;

- Engaged in reflective thinking and careful choice of words, which result in civil discourse;

- Developed an understanding of the art and science of applied ethics as related to the main challenges currently confronting the Information Profession.

The course is not a philosophy or religion course, but instead concentrates on the application of ethical reasoning to the Information Profession, with its many, diverse specializations. It is divided into three main sections: an introduction to applied ethics, the necessary steps for facing up to and resolving a moral dilemma and making a decision, and ethical issues in our field. The approach combines "knowing how" with "knowing why" and concentrates on the many questions to be asked in resolving complex issues, beginning with the individual. It is about each of us as an individual even though it is often easier to think of someone else's ethics, and also relates to interactions with other components of life (e.g., the environment, animals, etc.). The importance of the relationship between one individual and another and the need to learn to understand that each of us is a human worthy of respect - that we are fundamentally the same - is stressed. The -initial assignment is for students to read and reflect on the U.N. Universal Declaration of Human Rights and Martin Luther King's "I Have a Dream" speech and to write a short paper on the Fundamental Moral Experience. They then identify a personal problem or issue (whether related to personal or professional life) and work throughout the course towards solution of the problem.

For the course, the definition of ethics used is:

- Ethics is the art and science that seeks to bring sensitivity and method

- to the discernment of moral values. (Stephen Almagno)

Students read a series of books and articles, which change over time and are drawn from a number of disciplines, including philosophy, library and information science, business, and many others. The readings usually include at least two books, such as Stephen Carter's Integrity and the Dalai Lama's Ethics for the New Millennium, as well as articles from the Journal of Information Ethics, the Harvard Business Review and numerous other journals in the library and information field and from other disciplines.

Over the years, students who have taken the course have repeatedly sent letters or emails or verbally commented on the impact the course has had on their lives and how it has changed them. (Rockenbach, 1998) For example, she quotes one student, Leslie Lee, who wrote:

Of all my experiences in graduate school, the most enduring is the way Professor Almagno constantly challenged, encouraged and guided his Information Ethics students to love the questions. To me, that is precisely what the course is all about - being open and willing to examine life critically and to appreciate the process of ethical decision-making as much as, if not more than, the decision, itself.

\section{Models for Ethical Decision- Making}

\section{Context}

Several readings and references to websites (including ICIE's website) have been included 
throughout the course to provide the context for ethical reflection and decision-making, in particular to emphasize the importance of different perspectives from cultural, social, and individual viewpoints. This broader understanding is essential to any course, especially this course. The course is taught in English to English-speaking students and is thus limited in the readings that are used, although students are encouraged to bring in examples from their own readings in different languages and from experience in their own countries and cultures. I have consistently emphasized my own limitations and encouraged others to broaden the views of everyone in the course.

One very helpful, if complex, source for understanding context is Clare Beghtol's work on ethical warrant (Beghtol, 2002). Dr. Beghtol, who is on the faculty of the University of Toronto, Faculty of Information Studies, draws upon her extensive research to address problems of creating ethically based, globally accessible, and culturally acceptable knowledge representation and organization systems and foundation principles for the ethical treatment of different cultures. Basing her work on the U.N. Universal Declaration of Human Rights, she presents the concept of "cultural hospitality," to act as a theoretical framework for the ethical warrant of knowledge representation and organization systems. She concludes that the concept of cultural hospitality is promising for assessing the ethical foundations of systems for representing new knowledge and organizations systems and for revising existing systems. Reminding us that each individual belongs to a number of different cultures at different levels (e.g., living in one country, speaking different languages, adhering to policies and practices of different religions and/or political parties, belonging to different social organizations, etc.), she notes that individuals may and do legitimately disagree. She also argues that the boundaries among cultures can themselves be fuzzy and create tensions within an individual. In her discussions of the relationships of any particular culture to its information needs and systems and noting differences among oral and written cultures, she raises questions concerning what kinds of information people need; what they do with it; the extent to which they value it; and whether they choose to perpetuate the information. Her thoughtful, if somewhat densely packed, paper raises several questions, such as whether principles of cultural hospitality can be used to develop culture-neutral systems and theories, which deserve much more discussion. Her paper continues to stimulate thinking and discussion by students.

\section{The Wheel}

Over the fifteen years of teaching the course, we have used a series of models to assist students with ethical reflection and decision-making. Initially, Prof. Almagno used the model of a wheel with four groups of questions in the center hub: 1.) What; 2.) Why? How? Who? When? Where? 3) Foreseeable effects? And 4.) Viable alternatives. The spokes of the wheel are: Creative/imagination, reason/analysis, principles, affectivity, individual experience, group experience, authority, comedy, and tragedy. The questions in the hub provided questions for gathering information and to help in revealing other questions to be asked to determine reality. They also provide a reminder that ethical thinking requires dialogue, even if only with one 's self. The spokes serve as evaluation resources through which moral consciousness and awareness can unfold, and they provide a systematic process to address the concerns about how to evaluate each step in making a decision. While some students found the wheel helpful in assisting their decisionmaking process, many found the steps suggested by the spokes to be somewhat confusing and to overlap.

\section{Selected Frameworks}

\section{Mason et al.}

One example used is that proposed by Mason et al. in Ethics of Information Management (Mason et al., 1995). They remind the readers that ethical dialogues are dynamic and nonlinear and suggest a "checklist" of six considerations to be taken into account when resolving an ethical issue (Mason et al., 1995, pp. 103-104). These steps are:

1. What are the facts?

2. What ethical principles, standards, or norms should be applied?

3. Who should decide?

4. Who should benefit from the decision?

5. How should the decision be made?

6. What steps should be taken to prevent this issue from occurring again?

Step one relates to morally relevant considerations and requires both determining pertinent information (understanding the life cycles involved and identification of key decision-making processes) and 
identifying all the key stakeholders, their values, motivation, and physical history). This step establishes 'what is.' The second step concentrates on "what ought to be," and identifies ethical considerations to be applied. The third step seeks to identify who should take necessary actions, how to ensure that all stakeholders are included, and legitimacy and right to make decisions, as well as the ability to affect a resolution. Step four addresses the various benefits of all the stakeholders and how to balance these, including both short-term and long-run considerations. Step five addresses the method of decision-making, which must be and perceived to be fair and ethical. The final step recognizes that each decision becomes a precedent and seeks to decide what procedures should be used in the future and what decision will be best for the future. Of course, this process must be used within the specific context of the stakeholders making the decision and within the wider societal context.

This framework has been somewhat useful in the course, but many students have found that it does not provide sufficient guidance for them. A key problem is that is starts with gathering facts before reflecting on the questions related to fully understanding what are the initial questions to be asked to help identify exactly what problems and issues need to be addressed. Also, little guidance is provided to address other questions, especially the second one.

\section{Woodward}

The late Diana Woodward, formerly on the faculty of Drexel University, presents a framework for deciding issues in ethics (Woodward, 1990). She discusses advantages and disadvantages of consequentiality and deontology as bases for ethical reasoning in general, and intellectual freedom in general, concluding that a deontological defense of intellectual freedom is "safer" than one on consequential grounds. The article, while helpful for introducing some of the philosophical foundations and theoretical bases for ethical reasoning, does not provide a useful framework for addressing many practical, "real-world" issues.

\section{O'Boyle}

O'Boyle (O'Boyle, 2002) concentrates on the use of the Code of Ethics from the Association for Computing Machinery (ACM), described as deontological because of its enumeration of rights (what is owed by others) and duties (what is owed to others), within a general ethical decision-making process to determine an action. Providing a sound discussion of earlier writings on the ACM Code, he places the Code within a general ethical decisionmaking process, he differentiates between to human faculties: intellect and will. O'Boyle builds on work of Rest and Kohlberg and identifies a six-stage process: 1) Moral perception and personal knowledge of the moral good (recognition that the problem exists); 2) Moral discernment and personal ability to think logically (stating the problem clearly); 3) Moral resolution and personal ability to think analytically (tackling the complexities of the problem to arrive at an individual position); 4) Moral assessment and personal ability to assess one's freedom (assessment, including being aware of the double-edged sword of new technologies); 5) Moral decision and personal knowledge of one's duties (decision, including personal duty and obligations); and 6) Moral action and personal willingness to follow one's intellect (free will used to take action). O'Boyle finds that the ACM Code is helpful with the first three stages, but not with the other three, and that training is needed to apply the Code effectively. He raises two provocative suggestions: that implementing the Code could be advanced by 1 ) making an individual ethical audit part of an employee's performance review, and by 2) hiring people who have some understanding and training in ethical behavior. The students have found it helpful in applying codes of ethics to actual situations and problems, and they find the questions to be provocative. Because the article concentrates specifically on the ACM Code, the six-stage framework also has limitations. Also, it does not include extensive discussion of the various needs and perspectives of the various stakeholders, nor does it address many of the complex cultural issues.

\section{Examples from the Corporate Sector}

Because many SIS students work in, or will work in, corporate environments, articles from business journals and speakers from the corporate world are included in the course. One example is a model for ethical decision-making proposed by Gerald Ottoson (Ottoson, 1988), a retired industry executive, who is now a consultant. Ottoson has conducted numerous ethics seminars over the years for workers in corporations. His approach is to spend a small amount of time on fundamental ethical values (e.g., honesty, mercy, justice, etc.) and to concentrate on models to examine real cases. One model, "A Suggested Pattern of Inquiry," is presented as a checklist in reviewing and evaluating past actions. The model uses a series of questions: 1) Who should make the decision (includes where the 
legitimate power to make the decision lies, limits on authority, obligation/responsibility, need for knowledge-the essential facts, and neutrality/objectivity); 2) Who are the stakeholders (principle of regard for others); 3) What are the alternatives (including competing claims, costs/benefits, etc.); and 4) How should the decision be reached (inclusion in the process, perception of involvement, avoidance of paternalism). He notes that decision-making is always a compromise; there is no "perfect" solution; and that there will always be some regrettable aspects of the ultimate decision. He also realistically argues that the "final course of action you decide to follow should leave you a little uncomfortable. . .No matter how noble your purpose may be, there is no ethical reward for impaling yourself on someone else's sword." (Ottoson, 1988, 14) While his framework is incomplete and open to many different interpretations, the students find this example, used in conjunction with others, to be helpful because of its emphasis on the workplace and its realistic questions.

John Hammond et al. present a series of "hidden traps" in decision making in their article in the Harvard Business Review (Hammond et al., 1998). Although their work addresses decision making in the corporate world, the traps they identify can be applied to other types of work environments. Among the traps they identify are: 1) anchoring (giving disproportionate weight to the first information received; first impressions, facts, and estimates anchor subsequent thoughts and decisions); 2) status-quo (bias towards perpetuating the status quo and avoiding change); 3) sunk-cost (justifying past choices even when they no longer seem valid because investments have already been made); 4) confirming-evidence (seeking information that supports existing views while avoiding information that contradicts it); 5)framing (how the question is framed shapes the decision-making process and there is a tendency to adopt the frame presented rather than to restate the problem and reframe the questions); 6) estimating and forecasting (making and using estimates and forecasts without gauging accuracy and getting sufficient feedback); 7) overconfidence (tendency to be overconfident in making predictions); 8) prudence (being overly cautious); and 9) recallability (selectivity in examining past events and tending to exaggerate and assign higher probability to dramatic events). While this is not a framework for decisionmaking, consideration and discussion of these potential traps lead to an improved understanding of problems which are often encountered in ethical reflection and decision-making.

Dr. Christine Altenburger, a retired faculty member from the University of Pittsburgh Graduate School of Public and International Affairs, taught applied ethics for many years. In her teaching, she developed a series of principles and a framework (unpublished), which she has given permission to use in our classes. The basic principles she identifies, summarized from those frequently found in the literature, are: 1) Do no harm. Do good if possible. 2) Observe the cannons of justice. Be fair. 3) Respect the rights, dignity, and freedom of all individuals. She also presents a flow diagram, beginning with gathering facts, leading to analysis and judgment, and incorporating decision loops to reconsider answers to questions.

\section{Models used in SIS Class}

These and numerous readings have been used throughout our course, but none provided the kind of framework or guide needed for our students as they worked towards resolutions of their problems. One very helpful resource I have used is The Miniature Guide to Critical Thinking Concept and Tools by Richard Paul and Linda Elder from the Foundation for Critical Thinking (Paul and Elder, 2001). This brief Guide provides a concise discussion of the importance of critical thinking and the elements of thought, a checklist for reasoning, and a series of questions using these elements. It also summarizes problems of egocentric thinking (Paul and Elder, 2001, p. 6): 1) the assumption that it's true because I believe it; 2) true because we believe it; 3) true because I want to believe it; 4) true because I have always believed it; and 5) true because it is in my selfish interest to believe it. The Guide also presents questions related to universal intellectual standards, addressing: clarity, accuracy, precision, relevance, depth, breadth, logic, significance, and fairness and provides a template for analysis.

As I was teaching the course early in 2003, Paul and Elder issued The Miniature Guide to Understanding the Foundations of Ethical Reasoning (Paul and Elder, 2003), which has proven for me to be the most useful model. The Guide builds on the earlier one and introduces a concise and straightforward introduction to the function of ethics, expanding on the discussion of egocentric thought, and addressing problems of "pseudo-ethics". It discusses the differences between ethics and: religion, social conventions, sexual taboos, political ideology, and 
the law. The authors also remind the readers of why it is important to distinguish among questions of ethics, social conventions, religion and law, and they present a series of elements of ethical reasoning. They propose an eight-step process to determine the logic of an ethical question: 1) purpose (considering an individual's rights and needs as well as those of others); 2) key ethical question(s); 3) information needed to answer the question(s); 4) concepts and principles to guide thinking; 5) main assumptions used; 6) points of view of all stakeholders; 7) main inferences/conclusions (what are the alternatives, are all being considered, etc.); and 8) implications (for self and others, including consequences, questions of harm/good, etc.).

This framework has worked successfully for students to address a wide range of questions and problems. I have also used it effectively as part of a brief introduction to Information Ethics is our required introductory course for Library and Information Science Students, "Understanding Information," and in a continuing education workshop for medical librarians. In the introductory course, students worked in groups of six to discuss the process they would use (walking through the eight steps) to respond to a hypothetical example based on a realworld case in which a challenge requesting removal of some books was made in a school library. The students are told they are school librarians asked by the school's principal to recommend a response to the challenge before the school's board. In each case, the students indicated that the framework encourages them to ask many questions and to examine different perspectives and issues. They also noted the usefulness of the framework in working through individual problems. A significant flaw in the framework is that it addresses logic and does not recognize the individual's emotions and subjective feelings. This leads to a discussion of the importance of recognizing that no human is ever totally objective and of learning one's own biases, personal values, and cultural perspectives.

The Guide seems to be the best tool in our courses to help students work through ethical reflection towards making moral decisions, because it focuses on steps in critical thinking and encourages students to work through the steps, looping back to earlier steps, in the process. It also serves to help stimulate discussion among students and encourage raising questions about the many options to be considered throughout the steps. The major drawback to this Guide is that it does not address the emotional and more "human" aspects of decision making. The steps rely on logic and objectivity and do not take into account the fact that no human is ever completely objective. This shortcoming can, of course, be addressed by the teacher through readings and by raising questions in the discussion. A revised guide, addressing the subjective issues would be a valuable contribution to the teaching of ethical reasoning.

\section{Challenges of Teaching Diverse Students}

\section{Composition of the SIS Student Body}

The School of Information Sciences (SIS) at the University of Pittsburgh includes undergraduate students, who enter the program in their third (junior) year; master's students in one of three programs: Library and Information Science, Information Science, and Telecommunications; doctoral students, either in Library and Information Science or Information Science and Technology (specializing in one of those two areas). In addition, students from any program on campus may take SIS courses as long as they meet any prerequisite requirements or, for undergraduates, have permission of the instructor to take a graduate level course. Also, through a cooperative agreement, students from other universities, such as Carnegie Mellon, Chatham College and many other colleges and universities, may also take courses if they meet the requirements. Within SIS, itself, there are approximately 800 students from more than 30 different countries, and their backgrounds vary widely. In the LIS programs, most students come from humanities and social science backgrounds (with some from science and engineering backgrounds) and plan to work in libraries, archives, or other cultural institutions, although many do go on to work in government, industry and other settings in jobs ranging from school librarians, to archivists, to medical information specialists, to webmaster and others. IST students must have college mathematics and at least one programming language; many come from science and technology backgrounds, although a large number also have liberal arts backgrounds. About one-half of the graduate students work full time and many have significant family responsibilities; a large portion of the students have some work experience, and many have another graduate level degree (such as law, education, philosophy, literature, etc.). In addition, the faculty is diverse in the disciplines in which they studied and did research, their work experience, and 
the countries and cultures from which they come and in which they have worked. This diversity enriches the education of all students and the faculty, and it also raises a number of challenges for teaching and learning.

\section{Course Content}

Identifying what to include in a syllabus, both the topics and the readings, is difficult in many ways. Courses are fourteen or fifteen weeks long (depending on holidays), which means that a complex and large body of knowledge must be reduced to fit the time allowed. At SIS graduate courses meet once each week for two hour and fifty minute sessions, usually with a brief break. Many classes meet in the evening to meet the needs of the many students working full time. An information ethics course must provide an introduction to applied ethics, focus on a limited subset of the topic, and include resources to supplement what is included in the course content. Selecting readings is difficult because of language limitations (in our case, English), the need to choose a reasonable amount of material to be read each week, and the challenge of trying to provide international and multicultural perspectives. The inclusion of guest speakers from different types of organizations and, if at all possible, from different cultures and countries, can enhance the educational experience for the students.

\section{Teaching/learning Styles and Approaches}

Recognizing that students learn in different ways and come from backgrounds that include a wide range of teaching and learning styles, each instructor works to provide options and, if possible, customized approaches, for different students. For example, students from cultures that do not permit or encourage questioning the instructor or challenging ideas, often have difficulty participating in a U.S. seminar-style class in which students are expected to discuss readings and challenge ideas openly. Patience, some one-on-one sessions, and emphasis on civil discourse and encouragement of participation usually help with this. Instructors also have to work to be flexible and to adapt their teaching methods, perhaps combining and alternating different methods to meet students' needs. They also need to recognize their own strengths and weaknesses and the styles they are most comfortable using, seeking assistance from other faculty or from teaching assistance groups on campus. This is a complex and challenging area that deserves much more attention, sharing of experience, and discussion.

\section{Alternative Models}

Different models may be needed to assist with ethical reflection and decision-making, recognizing cultural and other biases in each. A model that works well with graduates, may not work as well with undergraduate students. Cultural biases in some models may introduce barriers for some students. Continuing to explore alternatives and evaluating the effectiveness of various models are needed to encourage student learning and exploration. Incorporating models, diverse readings, active discussion and interaction among students, and perspectives from outside speakers provides opportunities for effective learning and enhances education.

\section{Need for Ongoing Evaluation}

Excellence in education requires continual evaluation, from students, colleagues, and one's self. Getting students to provide constructive criticism throughout a course is difficult, because of students' concerns about possible negative consequences, different cultural backgrounds, and other factors. Watching facial expressions and other body language can be helpful in observing students' responses, as, of course, can responses to questions and the nature of class discussions. Some instructors give quizzes or tests to determine how well students are understanding and learning.

Extremely important throughout any course is the provision of comments and other feedback to students on their work. Detailed comments on papers, discussions with students both in class and individually, and other means of communicating with students about their work are all critical to ensure that students know how well they are doing. Raising questions to them to provoke their thinking and to help guide their learning is also important.

Encouraging participation by students in class discussions is also important and several different techniques may be needed for different students. For example, for students whose first language is not English, I have encouraged brief statements by students in response to questions to "even the playing field." Asking each student to take a turn leading the discussion of a course reading, after the presentation of examples by the instructor and with adequate time for preparation, gives students an opportunity to raise questions of their colleagues and to gain confidence in participating in a seminar environment. 


\section{Many Other Challenges}

This is a very incomplete list of challenges to be addressed in teaching Information Ethics to a very diverse student body. It is presented to provoke questions and to help initiate discussion of this complex topic. Discussions at the ICIE Symposium in October 2004 are expected to contribute significantly to addressing the question of what are the challenges and how can they best be addressed as we seek to teach and learn Information Ethics.

\section{References}

Barnes, R.F. 1990. The Making of an Ethics Code. American Society for Information Science Bulletin. 16 (6). 24-25.

Bearman, Toni Carbo. 1981. Do We Need a Code of Ethics for Information Science? American Society for Information Science Bulletin 8(1). 36.

Buchanan, Elizabeth A. 2002. Information Ethics in a World-Wide Context. In: Rudinow, Joel and Anthony Graybosch. Ethics and Values in the Information Age. Wadsworth/Thomson Learning. 2002. 35-44.

Beghtol, Clare. 2002. A Proposed Ethical Warrant for Global Knowledge Representation and Organization Systems. Journal of Documentation. 58, no. 5 (2002), 507-532.

Carbo, Toni and Stephen Almagno. Information Ethics: The Duty, Privilege and Challenge of Educating Information Professionals. Library Trends. 49, no. 3 (Winter 2001). 510-518.

Carter, Stephen L. Integrity. New York: HarperPerennial, 1996.

Dalai Lama. Ethics for the New Millennium. Riverhead Books, New York, 1999.

Hammond, John S., Ralph L. Keeney, and Howard Raiffa. 1998. The Hidden Traps in Decision Making. Harvard Business Review, SeptemberOctober 1998. 47-58.

Mason, Richard O., Florence M. Mason, and Mary J. Culnan.1995. Ethics of Information Management. Sage, Thousand Oaks, California. 1995. 85-107.

O'Boyle, Edward J. 2002. An Ethical Decision-Making Process for Computing Professionals. Ethics and Information Technology. 4 (2002) 267-277.

Ottoson, Gerald H. A Model for Ethical DecisionMaking. 1988. Ethikos. July/August 1988. 8-11.

Rockenbach, Barbara. 1998. Information Ethics at the University of Pittsburgh. Journal of Information Ethics. 7 (Fall 1998) 13-18.
Woodward, Diana. A Framework for Deciding Issues in Ethics. 1990. Library Trends. 39 (summer \& Fall 1990). 8-17.

Proceedings of the symposium "Localizing the Internet. Ethical Issues in Intercultural Perspective" sponsored by Volkswagen*Stiftung*, 4-6 October 2004, Zentrum für Kunst und Medientechnologie (ZKM, Karlsruhe) 